\title{
Defining Southern Ocean fronts and their influence on biological and physical processes in a changing climate
}

\author{
Christopher Chapman ${ }^{1, *}$, Mary-Anne Lea ${ }^{2}$, Amelie Meyer ${ }^{2,3}$, Jean-Baptise Sallée ${ }^{4}$, and \\ Mark Hindell ${ }^{2}$
}

${ }^{1}$ CSIRO Oceans and Atmosphere, Hobart, Tasmania, Australia

${ }^{2}$ Institute for Marine and Antarctic Studies, University of Tasmania, Hobart, Tasmania, Australia

${ }^{3}$ Australian Research Council Centre of Excellence for Climate Extremes, University of Tasmania, Hobart, Tasmania, Australia

${ }^{4}$ Sorbonne Université, CNRS, LOCEAN, Paris, France

*chris.chapman@csiro.au

\begin{abstract}
The Southern Ocean is a critical component of the global climate system and an important ecoregion that contains a diverse range of interdependent flora and fauna. The Southern Ocean also hosts numerous fronts: sharp boundaries between waters with different characteristics. As they strongly influence exchanges between the ocean, atmosphere and cryosphere, fronts are of fundamental importance to the climate system. However, rapid advances in physical oceanography over the past 20 years have challenged previous definitions of fronts and their response to anthropogenic climate change. Here, we review the implications of this recent research for the study of climate, ecology and biology in the Southern Ocean. We include a frontal definition "user guide" to clarify the current debate and facilitate future research.
\end{abstract}

The Southern Ocean, generally defined as the global ocean south of about $35^{\circ} \mathrm{S}$ that encircles the Antarctic continent, is unique oceanographic environment due to the lack of continental barriers blocking its flow and the strong winds that blow over its surface $^{1}$. At large scales, the Southern Ocean is characterised by both the intense eastward flowing Antarctic Circumpolar Current (ACC), one of the most powerful current systems on Earth, and strongly tilted isopycnals (lines of constant density) that shallow to the south.

Observations of the Southern Ocean dating back to the Discovery expedition in the 1920s revealed that the transition from warmer subtropical waters to colder Antarctic waters does not occur smoothly, but is concentrated into a series of sharp transition zones, aligned generally east-west, that have come to be called fronts ${ }^{2}$. Further observations revealed that salinity, oxygen, nutrients and various other tracers showed similar behaviour, and that between the fronts, water properties are relatively homogeneous. As such, fronts delimit the boundaries between different water-masses with distinct environmental characteristics ${ }^{3}$. These fronts also tend to coincide with the location of narrow yet very intense currents known as "jets" that dominate the ACC's flow ${ }^{5}$. The Southern Ocean is divided by fronts into a number of distinct biophysical zones, and hence a number of distinct habitats, which in turn support distinct biota ${ }^{6,7}$. Numerous studies have shown that seabirds and marine mammals tend to congregate and forage in and around fronts ${ }^{7}$. As the Earth continues to warm due to anthropogenic climate change, it is vital that we understand how these fronts and jets will respond to changes in the global climate system, and what influence that might have on associated ecosystems ${ }^{8-10}$.

Due to its remoteness and harsh climate, undertaking field studies in the Southern Ocean is both difficult and expensive. As a result, the Southern Ocean is amongst the most data-sparse of all major ocean basins, which has hindered progress on key questions regarding its dynamics and ecological communities ${ }^{10}$. In recent decades however, a deluge of new data from satellites and Argo profiling floats, along with ever increasing numerical modelling capabilities, have dramatically changed our understanding of the Southern Ocean. Concurrently, advances in microelectronics have enabled researchers to track individual animals over long periods of time, and relate their behaviour to environmental conditions ${ }^{11}$.

The unprecedented detail provided by these new data has caused the community to question longstanding and fundamental 
ideas about the nature of the ACC and its fronts. In particular, seemingly simple questions such as: what is a front? how many fronts are there? are "fronts" and "jets" the same thing? and what role do fronts play in the Southern Ocean ecosystem? have been revisited as new data and methodologies have become available ${ }^{12}$. A changing conceptual understanding of the ACC has occasionally resulted in surprising disagreements: studies using the same data but different methodologies have arrived at dramatically different conclusions. The conflicting definitions of a front, the often technical nature of the debates, and the fact that the terms "front" and "jet" are often used interchangeably has resulted in a degree of confusion.

The purpose of this article is to summarise our current understanding of Southern Ocean fronts and the potential impact of recent research in physical oceanography outside of the domain. We will make clear areas of consensus and those where substantial debate still remains. Our synthesis is aimed at the the broader oceanographic community and marine biologists that may not have been aware of these recent advances or how to best exploit new data and techniques to answer outstanding questions. To this end, we include a Southern Ocean fronts "users guide" to facilitate future research.

\section{The Physical Oceanography of Southern Ocean Fronts}

The existence of fronts in the Southern Ocean has important implications for both the physical oceanography of the region and the entire climate system. For example, enhanced density gradients near fronts support, via thermal wind, strong jets. Frontal jets are responsible for the majority of the ACC transport and act as barriers to horizontal mixing: it is more difficult to move tracers across a jet than along it ${ }^{13-15}$. Frontal regions are also sites of pronounced exchange between the deep and surface ocean: both the upwelling (rising) of deeper waters and subduction (descending) of surface waters to the abyssal ocean is enhanced in frontal zones ${ }^{16,17}$. Additionally, fronts can catalyse the generation of meso-scale "eddies" 18,19 and sub-meso scale "filaments" which are able to bring nutrients from the deep ocean to the surface where they can be consumed by biological components of the system ${ }^{20,21}$. These details are shown schematically in Fig. 1.

Historically, fronts in the Southern Ocean have been defined as the boundary between two zones with distinct water-mass properties $^{2}$. By compiling hydrographic data obtained from research cruises over many decades, researchers built what has become known as the traditional view of Southern Ocean fronts: three fronts denoted, (from north to south) the Subantarctic Front; the Polar Front and the Southern ACC Front ${ }^{3,22}$ (Fig. 2a). Occasionally, the three front view is augmented by the addition of the Subtropical Front to the north, and the Southern Boundary Front near Antarctica, although their dynamics are distinct from the main ACC fronts, and, as such, are often not considered part of the ACC ${ }^{5}$. Each front was thought to be circumpolar in extent, deep reaching, co-located with prominent eastward flowing jets, and strongly steered by bathymetry ${ }^{3,22}$.

By necessity, the traditional view of ACC fronts was a time-averaged view: it took decades to assemble a database of hydrographic profiles capable of representing the broad-scale structure of the ACC. However, since fronts are sharp boundaries between two different water masses, they manifest as strong horizontal gradients in fields such as sea-surface temperature or sea-surface height that can be observed by satellites. With the availability of high-resolution satellite data in the 1980s and 1990s, it became apparent that the Southern Ocean is more complex than the traditional view would suggest (Fig. 2b) and that the ACC is not composed of a distinct number of coherent, circumpolar fronts, but of an intricate web of thin filaments that can spontaneously form and disappear, split and merge, meander and drift, bearing little resemblance to the traditional view of the ACC. Crucially, there is no settled answer to how many ACC fronts exist, as the number of fronts vary both temporally and spatially ${ }^{23-25}$.

During the satellite era, it was established that fronts in the Southern Ocean arise primarily by complicated, nonlinear interaction between the mean flow and turbulent eddies: In some regions of the ACC, meso-scale eddies accelerate jets and sharpen tracer gradients ${ }^{18,26}$. Jets also act to suppress mixing; regions with strong jets tend to have dramatically reduced meridional (north-south) exchange of heat and other tracers ${ }^{13}$. Conversely, regions with weaker jets, which typically occur downstream of large bathymetric features, the transport barrier effect is weaker, and elevated north-south exchanges are found in these "leaky" jet regions ${ }^{13,14,27-30}$.

Reconciling the traditional view of the ACC from hydrography and the new dynamic view provided by high-resolution satellite observations has, despite intense research, eluded satisfactory closure. Numerous studies have argued that the the major hydrographic fronts are composed of numerous branches: distinct coherent frontal features that can occasionally merge together in certain regions $5,24,31-34$. However, more recent research has cast some doubt on this interpretation, with several studies showing that the frontal structure of the ACC rearranges itself several times around the circumpolar circuit ${ }^{23,25,35}$, manifesting as the splitting of a single front into numerous sub-fronts, rather than coherent meandering of the individual frontal branches as suggested by earlier studies ${ }^{12,24,33}$. Evidence to date does not suggest that any one front maintains a continuous 


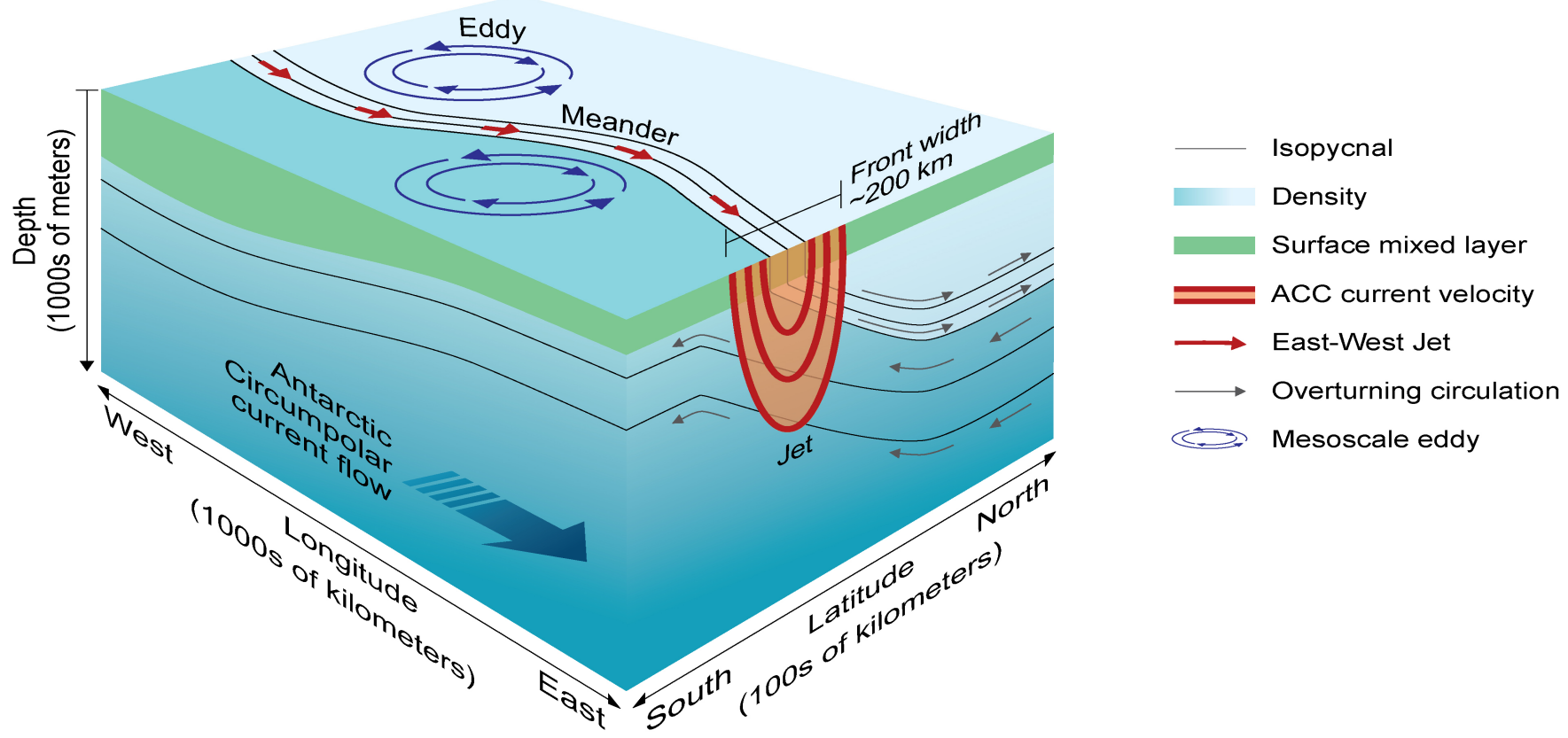

b

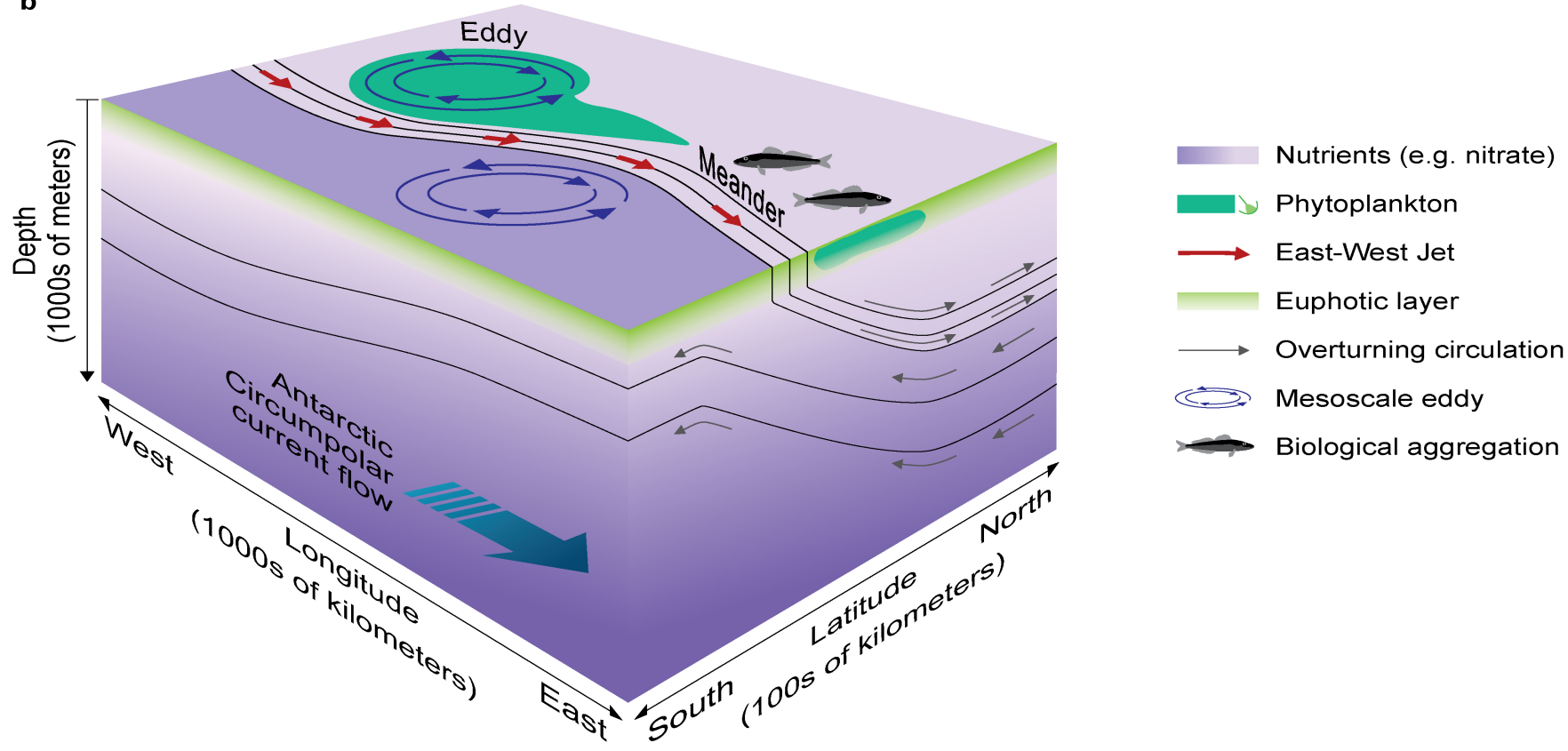

Figure 1. Illustrations of Antarctic Circumpolar Current fronts. Schematic showing the a physical and b biogeochemical characteristics of an idealized ACC front. In the frontal region, isopycnals are bunched closely together and slope strongly towards the surface. Strong geostrophic ocean currents, known as jets, are associated with the density front due to the thermal wind relationship. The front separates regions of high and low density (a), and high and low nutrient concentrations (b), as the jet tends to inhibit cross-frontal exchange. Straining by the jet and the downstream transport of nutrients such as iron acts to deform and elongate an idealized chlorophyll patch (b), and upwelling/subduction of water associated with the overturning circulation is indicated by thin arrows. 
a
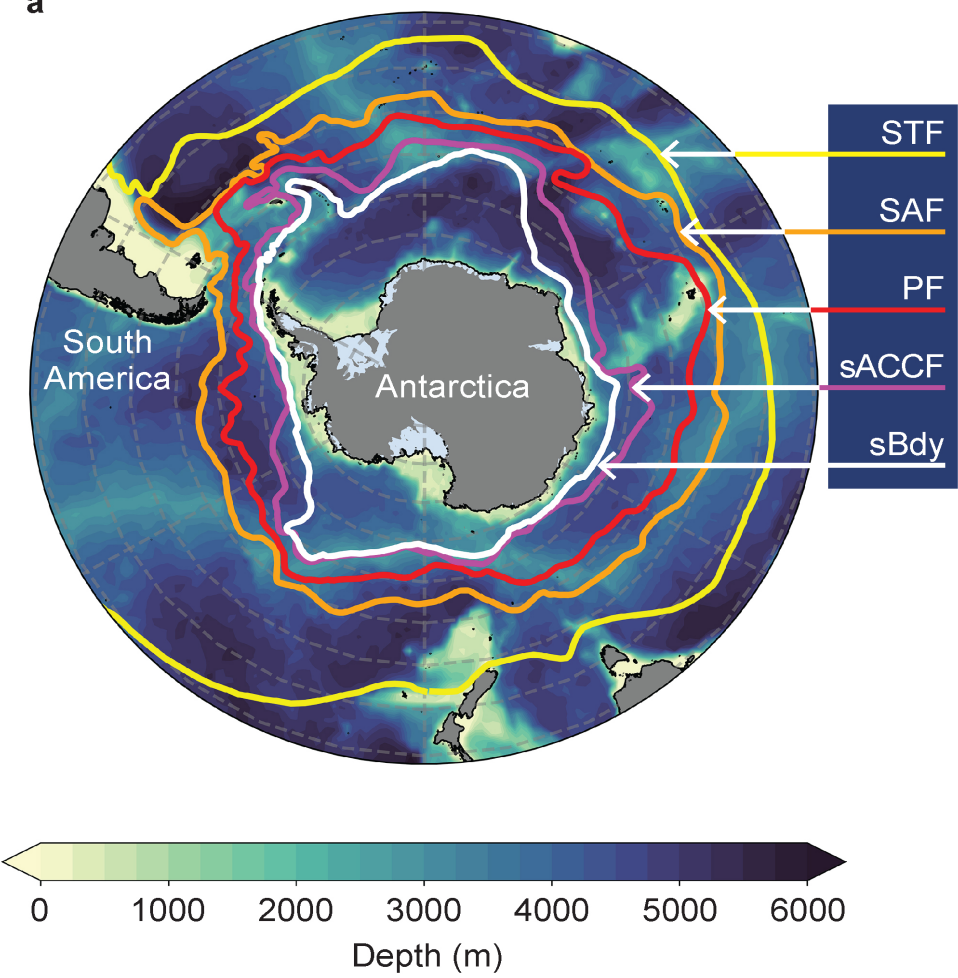

b

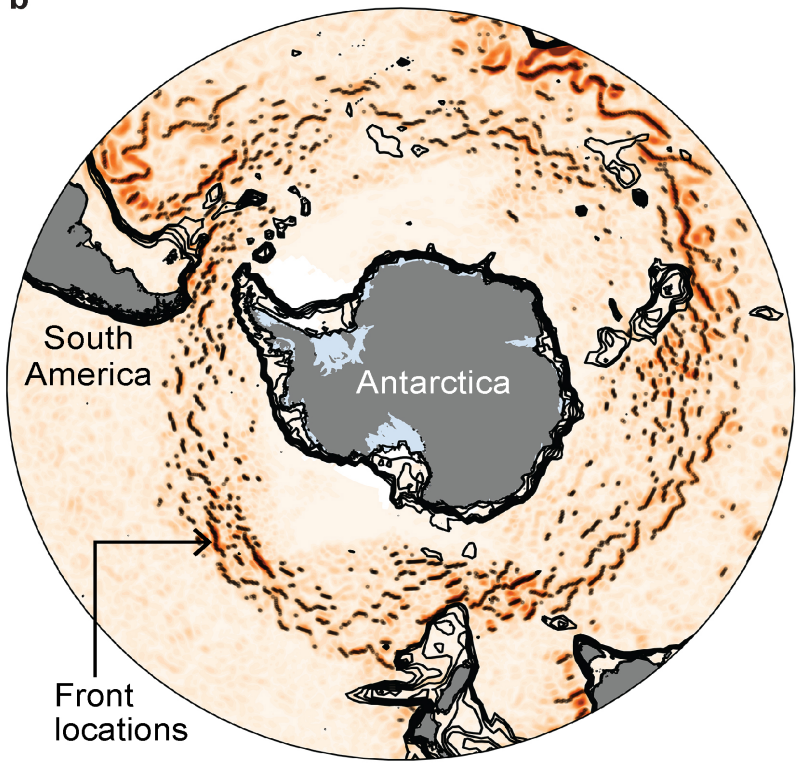

11 January 2010

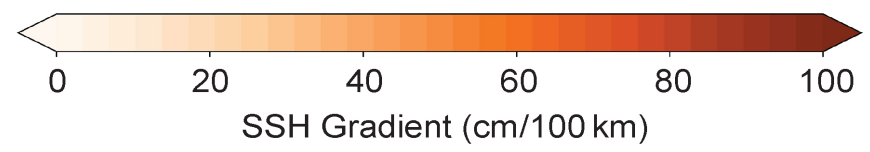

Figure 2. The changing conception of the Antarctic Circumpolar Current and its fronts: a smooth, continuous, circumpolar fronts determined by Orsi and collaborators ${ }^{3}$ using historical hydrographic data and applying water mass criteria (for example, a particular temperature value at a certain depth) to define their locations. The named fronts are, north to south, the subtropical front (STF); the subantarctic (SAF); the polar (PF); the southern ACC (sACCF); and the Southern Boundary (SBdy) fronts. Colors show the ocean depth, illustrating the strong steering of the fronts by submarine bathymetric features. $\mathbf{b}$ A daily snapshot (11th of January, 2010) of the gradient of Sea-Surface Height (SSH) obtained from the gridded AVISO satellite altimetry product (colors). Broken black lines indicate the location of fronts or jets on this date determined by SSH gradient thresholding ${ }^{25}$. Solids contour lines are isobaths (contour interval of $1000 \mathrm{~m}$ ).

structure over the entire $\mathrm{ACC}^{25,35,36}$.

\section{Practical Definitions of Fronts}

In his seminal review of fluid dynamical jets, Rhines stated that "It is not easy to give a precise definition of a jet of fluid motion, but most of us know one when we see it" ${ }^{37}$. This statement could also apply to Southern Ocean fronts: while the conceptual idea of a front as a water-mass boundary is universally accepted, there is no single, precise definition of a front. In practice, a wide variety of definitions are used ${ }^{12}$. Inconsistent frontal definitions, and conflicting nomenclature has led to a great deal of confusion about what is, and what is not, a front ${ }^{38}$.

Early studies based on hydrographic data typically used water-mass criteria, such as a particular value of temperature, to define a front ${ }^{3,22}$. However, with the changing view of the ACC, these definitions have been reevaluated. Currently, frontal definitions fall into two broad classes ${ }^{12}$ :

1. Local definitions use criteria found in the immediate neighbourhood of a geographic location to determine if a front is present. Gradient thresholding is probably the most commonly employed local method: a front is detected should the gradient of some quantity (typically sea-surface temperature (SST) ${ }^{39-41}$ or sea-surface height $(\mathrm{SSH})^{12,25,26}$ ) exceed some pre-defined threshold. However, other local definitions exist, such as those based on statistical properties ${ }^{14,27,36,42}$ or the dissimilarity of nearby hydrographic profiles ${ }^{43,44}$. Locally defined fronts are not necessarily continuous, and the number of fronts can vary in space and time; 
2. Global definitions seek to identify some quantity, for example a particular value of temperature or SSH, that one can use to identify a front over some region, or even the entire $\mathrm{ACC}^{5}$. Fronts defined using global definitions are generally continuous in space and the number of fronts is chosen a priori $^{24}$.

Typically, biologists define fronts based on SST criteria, while physical oceanographers generally use SSH. There is a subtle difference between these oceanographic variables: the SST seen by satellites is strictly the near surface temperature, while the SSH is a function of both the temperature and salinity throughout the entire water column. As such, SST reflects surface ocean conditions, while SSH is influenced by both surface and sub-surface processes.

That global frontal definitions resemble older water-mass definitions is no coincidence, as they arose from work seeking to resolve the discrepancy between the traditional and dynamic views of the ACC. These studies showed that regions of, for example, high sea-surface height gradients were consistently associated with both hydrographic fronts and particular values of sea-surface height itself $f^{4,5,31-34}$. By finding the sea-surface height or temperature value most closely associated with high gradients or water-mass criteria, one obtains a definition of a front that is both time variable, yet spatially continuous.

However, it has been shown that the value of temperature or SSH associated with a particular front may not perfectly align with high gradient regions over the entire region of interest, leading to the suggestion of the presence of a front where it may, in fact, be absent ${ }^{35}$. Additionally, the frontal structure is variable in both time and space, and a value of (for example) SSH representative of a front at one location or time may not be representative at another ${ }^{14,25,35,36}$. These phenomena are illustrated in Fig 3, which shows a time-series of the gradient of satellite derived SSH at two longitudes in the Southern Ocean, together with contours of SSH associated with five major ACC fronts. While the SSH contours represent the mean positions of the fronts very well, the contours frequently drift off high gradient regions, or persist during periods without high SSH gradients.

Both local and global definitions of fronts have advantages and disadvantages, and the choice of definition must be based on the nature of the scientific question being posed. Advice for choosing frontal definitions is presented in Sec. 5

\section{Fronts, Biogeochemistry and Ecosystems in the Southern Ocean}

The unique oceanographic conditions of the Southern Ocean have profound implications for the ecology of the region and biogeochemical cycles that influence the climate system. As a result of its steeply sloped isopycnals, it is in the Southern Ocean that nutrient and $\mathrm{CO}_{2}$ rich deep water masses, so-called as they are found at a depth greater than $1 \mathrm{~km}$ throughout most of the global ocean, upwell to the ocean surface ${ }^{16}$. Once at the ocean surface, these formerly deep waters are able to exchange heat and $\mathrm{CO}_{2}$ with the atmosphere ${ }^{45}$, and their nutrients may be consumed by biology confined to the euphotic zone ${ }^{7}$.

Southern Ocean fronts are thought to play a key role in the global distribution of important nutrients, such as nitrates, through two primary mechanisms ${ }^{46}$ :

1. fronts act as sites of enhanced vertical exchange between the deep and surface ocean; and

2. the "mixing barrier" effect for frontal jets reduces the exchange of tracers across fronts;

Throughout most of the global ocean, less dense, nutrient poor water-masses are vertically stacked on top of dense, nutrient rich water-masses. However, in the Southern Ocean, the intense upwelling (localised in frontal regions) results in vertical property gradients being tilted sideways, and therefore becoming horizontal property gradients. The mixing barrier effect then inhibits the exchange of these upwelled waters with neighbouring nutrient poor watermasses, forming biogeochemical fronts ${ }^{46,47}$ (see Fig. $4 a, c)$.

However, there is a paucity of high resolution biogeochemical data in the Southern Ocean. As such, the impact of the filamented, dynamic fronts (discussed in Sec. 1) on the nutrients and other tracers is poorly understood. However, recent work has shown that the upwelling and subduction in the Southern Ocean is controlled by the complex interactions between the frontal jets, large bathymetric features, and surface winds ${ }^{45,48,49}$. As such, the upwelling of nutrients and subduction of $\mathrm{CO}_{2}$ into the ocean interior is localized to regions where fronts interact with bathymetry ${ }^{49-51}$.

Similar frontal dynamics also influence the ecology of the Southern Ocean from the base to the top of the trophic chain. While upwelling of deep waters supplies the Southern Ocean with large quantities of nitrates, phosphates and silicates, the region is a known "high nutrient, low chlorophyll" zone due to iron limitation ${ }^{52,53}$. However, downstream of several islands scattered throughout the Southern Ocean, as well as near the South American continental shelf, phytoplankton concentrations can be relatively high ${ }^{52,54-56}$, as illustrated in Fig. 4 b,c using satellite derived chlorophyll-a concentrations ${ }^{57}$. Phytoplankton blooms 


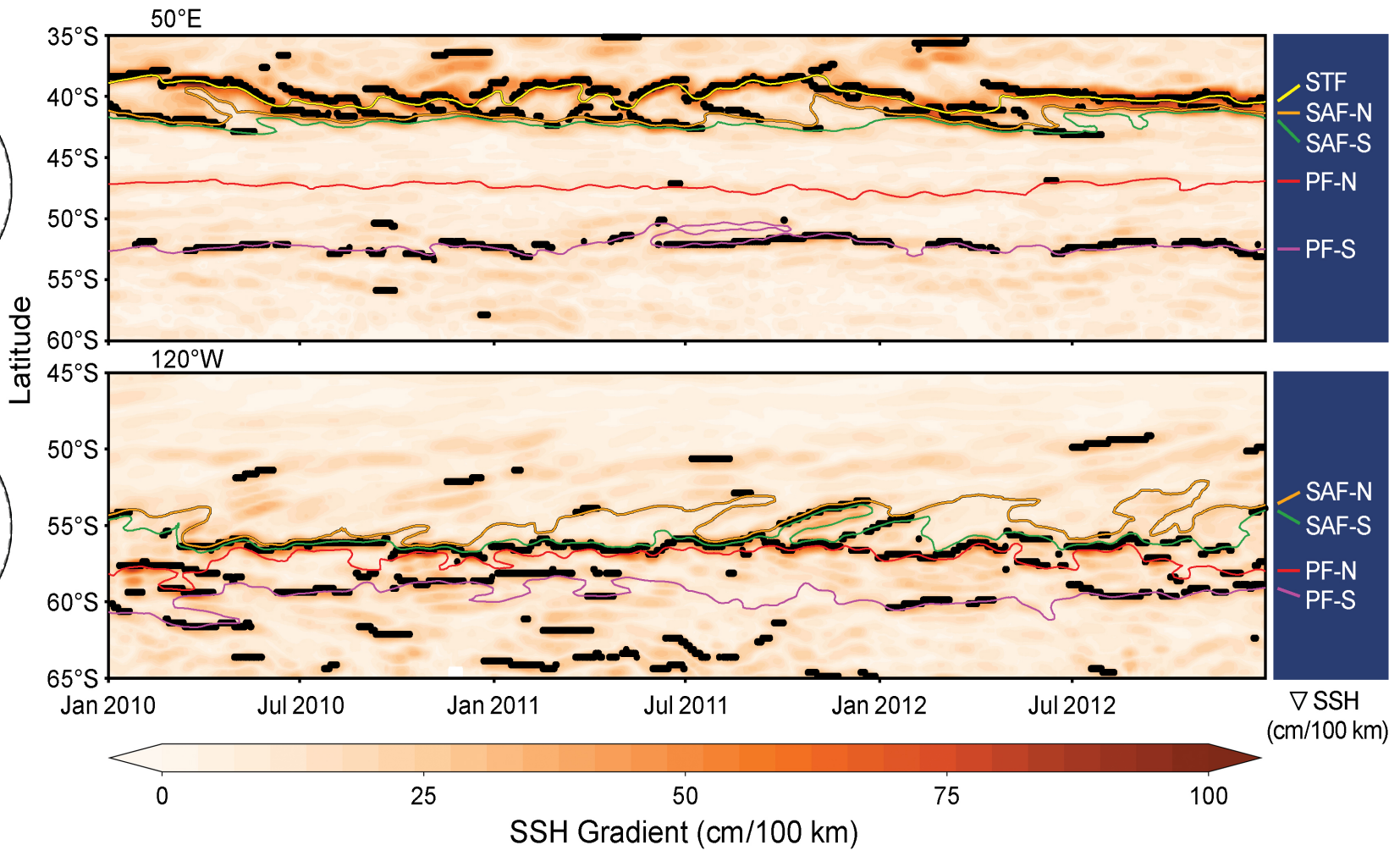

Figure 3. A cautionary example of using sea-surface height to track fronts. Colors show a latitude/time (Hovmöller) diagrams of sea-surface height gradient (obtained from the AVISO gridded satellite altimetry product) from the 1st of January 2010 to the 31st of December 2013 at locations in the (a) south-west Indian Ocean and (b) central-south Pacific Ocean. The thin solid lines are five contours of SSH, corresponding to values that best define (from north to south) the sub-tropical front (STF), northern and southern branches of the subantarctic front (SAF-N and SAF-S); and northern and southern branches of the polar front (PF-N and PF-S), the values themselves are taken from Chapman $(2017)^{25}$. The black dots indicate the location of fronts determined from SSH gradient thresholding ${ }^{25}$. The SSH contours do not always follow the high SSH gradient regions and occasionally identifies fronts where gradients are weak. This example is inspired by the work of Graham and colleagues ${ }^{35}$

are initiated in regions where frontal jets interact with bathymetry, bringing iron-rich sediments to the surface $e^{49,54}$. Jets then export these high iron concentrations downstream, which can extend phytoplankton blooms hundreds or even thousands of kilometers downstream of the iron source regions ${ }^{56}$, as shown for the Kerguelen Plateau region in Fig. 4d. Zooplankton that graze on phytoplankton, such as krill, congregate in these productive regions, and are, in turn, targeted by many larger Antarctic predators, including fish, squid, seabirds and mammals ${ }^{58-60}$ (Fig. 4e).

At the fronts themselves, the dynamic nature of the oceanography may result in increased biomass and biodiversity as the inter-frontal communities interact ${ }^{58}$. This increased biodiversity also influence the distribution and behaviour of organisms at higher trophic levels ${ }^{7}$. Fronts create ecological niches occupied by particular species ${ }^{20,54,55,62}$. For example, King penguins (Aptenodytes forsteri) forage in the Antarctic Polar Frontal Zone and target meso-scale features such as thermal fronts ${ }^{63-67}$, travelling further in years when the position of the front is further from their breeding and moulting grounds ${ }^{68,69}$. Southern Ocean seabird assemblages are reported as being associated with specific water masses, including interfrontal zones ${ }^{70-72}$. There is evidence that marine predators use environmental conditions, such as temperature, as an indication of prey availability ${ }^{67}$.

The relationship between fronts and the distribution of marine animals is less clear than that for phyto and zooplankton, due to their capacity to conduct basin-scale movements and the dictates of species-specific life histories. For example, Antarctic fur seals (Arctocephalus gazella) travel to the Antarctic Polar Frontal Zone ${ }^{73-75}$ to take advantage of elevated productivity shaped by the large-scale oceanography ${ }^{76}$, while southern elephant seal (Mirounga leonina) populations can be divided into "locals" that exploit a few frontal features, or "roamers" who forage in multiple different heterogeneous environments ${ }^{77}$. Central place foragers, such as seals and penguins, need to regularly return to breeding sites, whereas some species, such as the wandering albatross (Diomedea exulans), can range over vast distances ${ }^{78}$. 


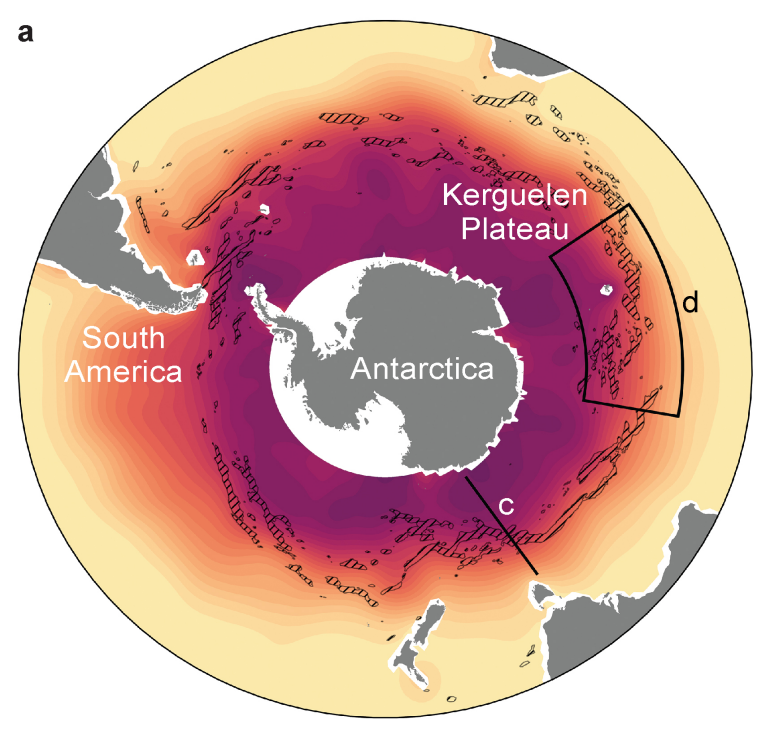

c

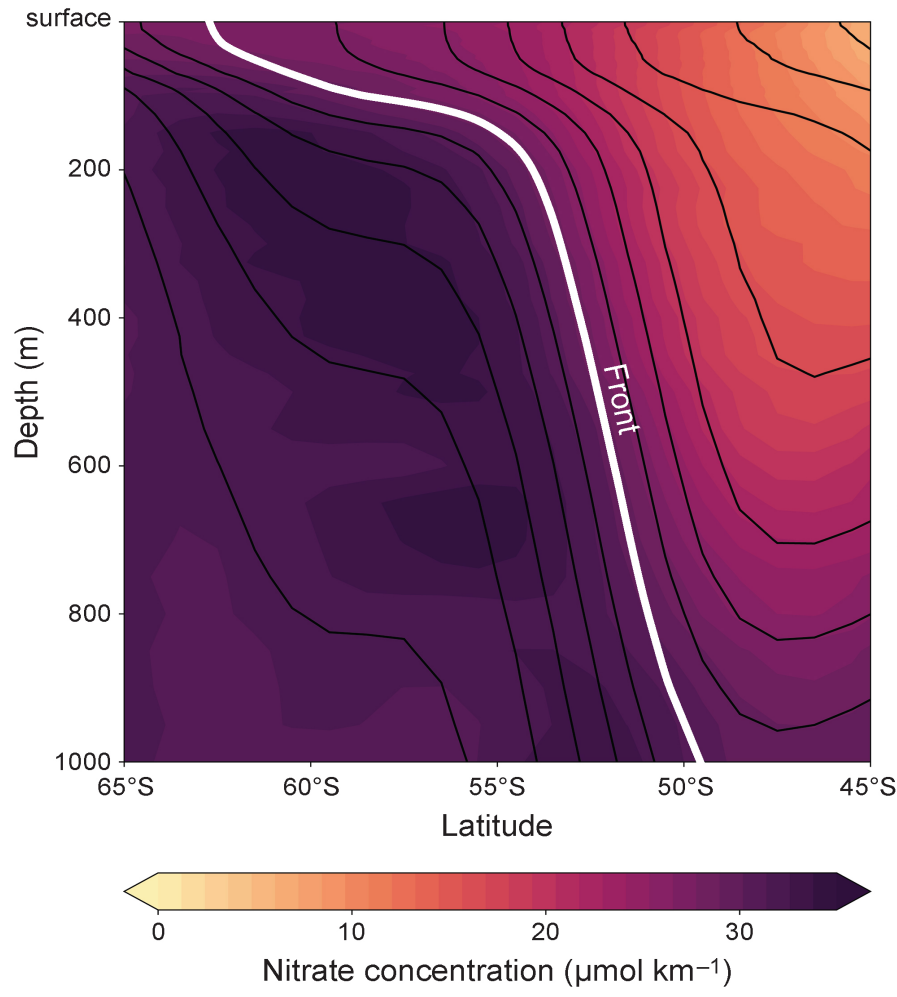

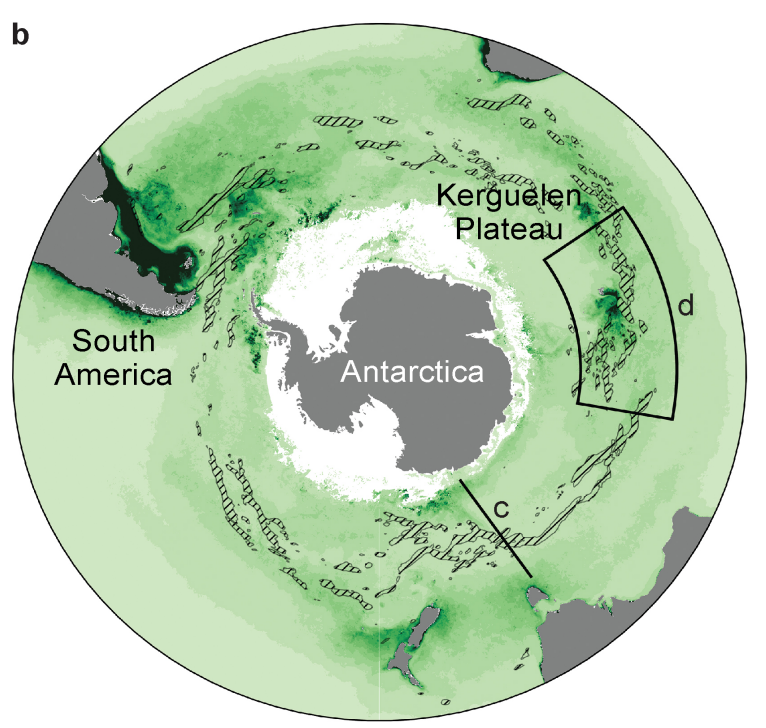
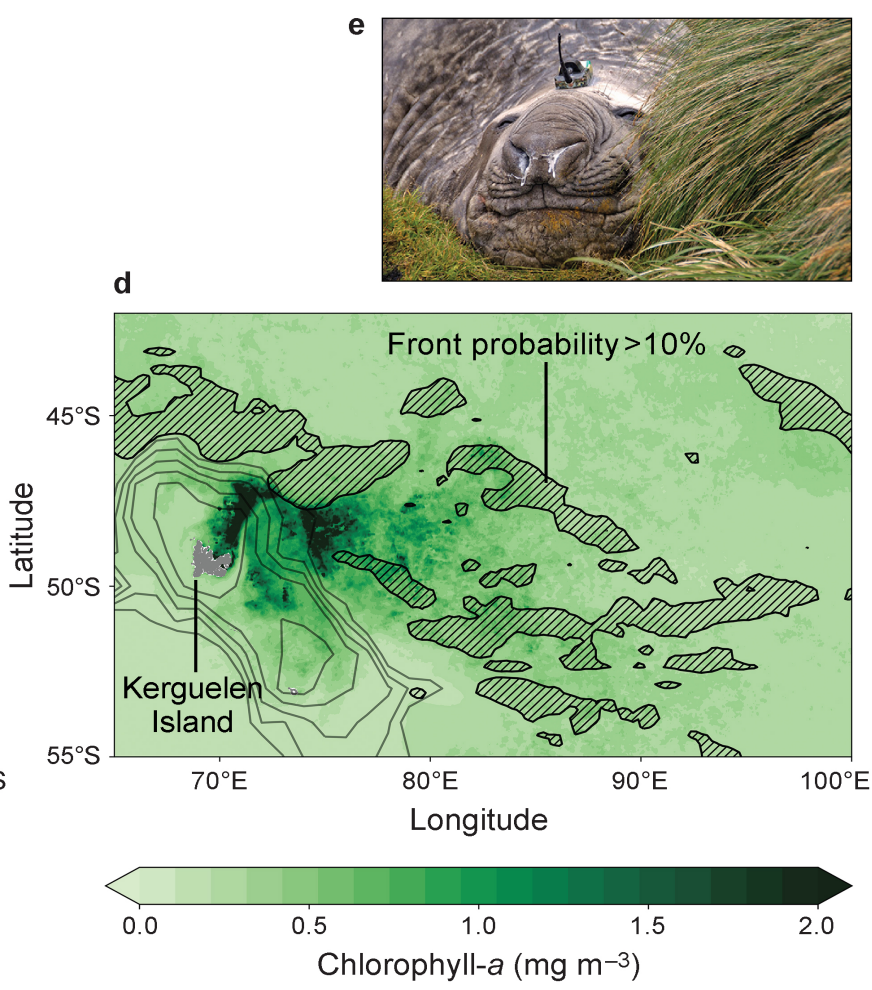

Figure 4. The influence of fronts on nutrients and phytoplankton blooms. a The springtime (September to December) mean concentrations of nitrates $\left(\mathrm{NO}_{3}^{-}\right.$) from from the World Ocean Atlas 2018 (WOA18) ${ }^{61}$; b 2003-2018 November time mean Chlorophyll-a concentration, a proxy for phytoplankton concentration, from MODIS ocean color satellite system ${ }^{57}$. c Depth/latitude transect between Tasmania and Antarctica (along $140^{\circ}$, shown as a thin black line in panel a) showing the spring mean WOA18 nitrate concentration from the surface to $1000 \mathrm{~m}$ depth. The thin black lines are lines of constant surface referenced potential density $\left(\sigma_{0}\right)$, also from WOA18, while the white line shows the approximate location of the nitrate front; d MODIS 2003-2018 November time mean chlorophyll-a concentrations near Kerguelen Island, showing the extent of the seasonal bloom. Thin grey lines are baythmetric contours (contour interval: $500 \mathrm{~m}$ ). In panels $\mathbf{a}, \mathbf{b}$ and $\mathbf{c}$, hatching shows regions where the probability of encountering a front is greater than $10 \%$ (from Chapman $2017^{25}$ ); and e A Kerguelen southern elephant seal, equipped with a miniaturized temperature, salinity and depth sensor. Southern Elephant seals are known to forage in the Kerguelen phytoplankton plume (photo: Mark Hindell) 
Great advances in biotelemetry tools for animal tracking, coupled with the availability of higher resolution ocean observations, have enabled greater understanding of relationships between marine animals and complex ocean processes. For example, southern elephant seals and macaroni penguins (Eudyptes chrysolophus) are now known to interact with and forage in regions of high eddy formation and filaments associated with ACC fronts ${ }^{79-83}$. However, the relationships between biology and environmental conditions are often qualitative ${ }^{84}$ or restricted to a small number of individuals ${ }^{80}$. As such, the challenge for biologists is to integrate observations of animal behaviours with the fine-scale physical and biological properties of Southern Ocean fronts. Earlier perceptions of Southern Ocean fronts as a "line in the sea" can be too simplistic, and at odds with what is now known about the behaviour of many predators. Recognition of the spatial and temporal dynamics of fronts, along with tools that enable biologists to identify oceanographic features at scales and times congruent with the behavior of marine predators, will enable deeper insights into the factors that limit biological production, how this propagates up the food chain, and why organisms aggregate where they do.

\section{Climate Change and Southern Ocean Fronts}

The Southern Ocean is both warming ${ }^{8,85}$ and freshening ${ }^{85,86}$ and there is evidence that the strong westerly winds that drive the ACC are both intensifying and shifting to the south ${ }^{87}$. These trends are expected to continue with ongoing climate change ${ }^{50,88,89}$. Given the importance of ACC fronts to the ecosystems of the Southern Ocean and the climate system, assessing and predicting how they will respond to a changing climate is vital. However, research on this question has suffered from much of the same confusion that pervades the literature on ACC fronts as a whole due to inconsistent frontal definitions, nomenclature and methodologies. In this section, we discuss the observed and projected changes in ACC fronts and the implications of such changes on Southern Ocean ecosystems.

\subsection{Observed and projected changes in Southern Ocean fronts}

Studies of trends in the structure or position of ACC fronts and jets have been hampered by a lack of long term observations ${ }^{1}$. However, the development of the "contour" type methods described in section 2 that link hydrographic fronts with surface phenomena observed by satellites, enabled the multi-decade long satellite record to be exploited to study the variability of ACC fronts. A wave of studies using these methods established a tentative consensus: over the satellite altimetry period (from 1993 onwards) the main fronts of the Southern Ocean had generally shifted south by $\sim 0.5-1.5^{\circ}$ (60 km on average) over a period of around 15 years ${ }^{31,33,34,90}$. Frontal variability was found to be larger away from large bathymetry which tends to constrain frontal movements. Several of these studies noted that the position of ACC fronts were sensitive to changes in atmospheric forcing due to large-scale climate modes such as El-Niño/La-Niña ${ }^{31,34}$. These conclusions were generally supported by studies using the previous generation of climate models (those associated with the Coupled-Model Intercomparison Project 3 (CMIP3) multi-model ensemble), that projected a poleward trend in frontal locations driven by changes in winds, and would likely continue into the future ${ }^{87,91}$. On the strength of the consensus that emerged between 2007 and 2015, the observed warming in the Southern Ocean was interpreted as a signature of regionally localized southward shifts of the ACC fronts $8,33,92,93$.

The primary assumption of these analyses is that if a contour SSH shifts, then its associated fronts will shift with it. However, more recent work employing "local" definitions (see section 2) has shown that this is not necessarily true, with numerous studies failing to detect any long-term trend in the position of the ACC fronts ${ }^{19,25,41,42,94,95}$, although there is some evidence of localized frontal movements and changes in frontal intensity ${ }^{40,41}$. Additionally, some recent studies provide only limited evidence of a systematic response of fronts to changing atmospheric forcing ${ }^{25,35,42}$. More modern climate models, such as those within the CMIP5 multi-model ensemble, show no systematic shift in frontal locations ${ }^{35,85,89,96}$. Instead, most recent modelling studies predict an increase in the strength of the Southern Ocean's eddy field and stratification, as well as a moderate increase in the rate of upwelling of deep waters ${ }^{16}$.

In Fig. 5 we illustrate the projected Southern Ocean climate change using output from a modern climate model, the GFDL-ESM2M ${ }^{97}$, forced by two greenhouse gas concentration scenarios: a medium (Representative Concentration Pathway 4.5), and a high (Representative Concentration Pathway 8.5) emissions scenario. In both cases, the temperature of the Southern Ocean is projected to increase substantially, which would result in a significant southward shift of SST and SSH contours by the year 2100. However, in both climate projections considered here, there is little to no shift in position of either regions of high SSH gradients (dashed contours in Fig. 5a,b,c) or strong isopycnal slopes (dashed contours in Fig. 5d,e,f), which are indicative of fronts and strong ocean currents. 

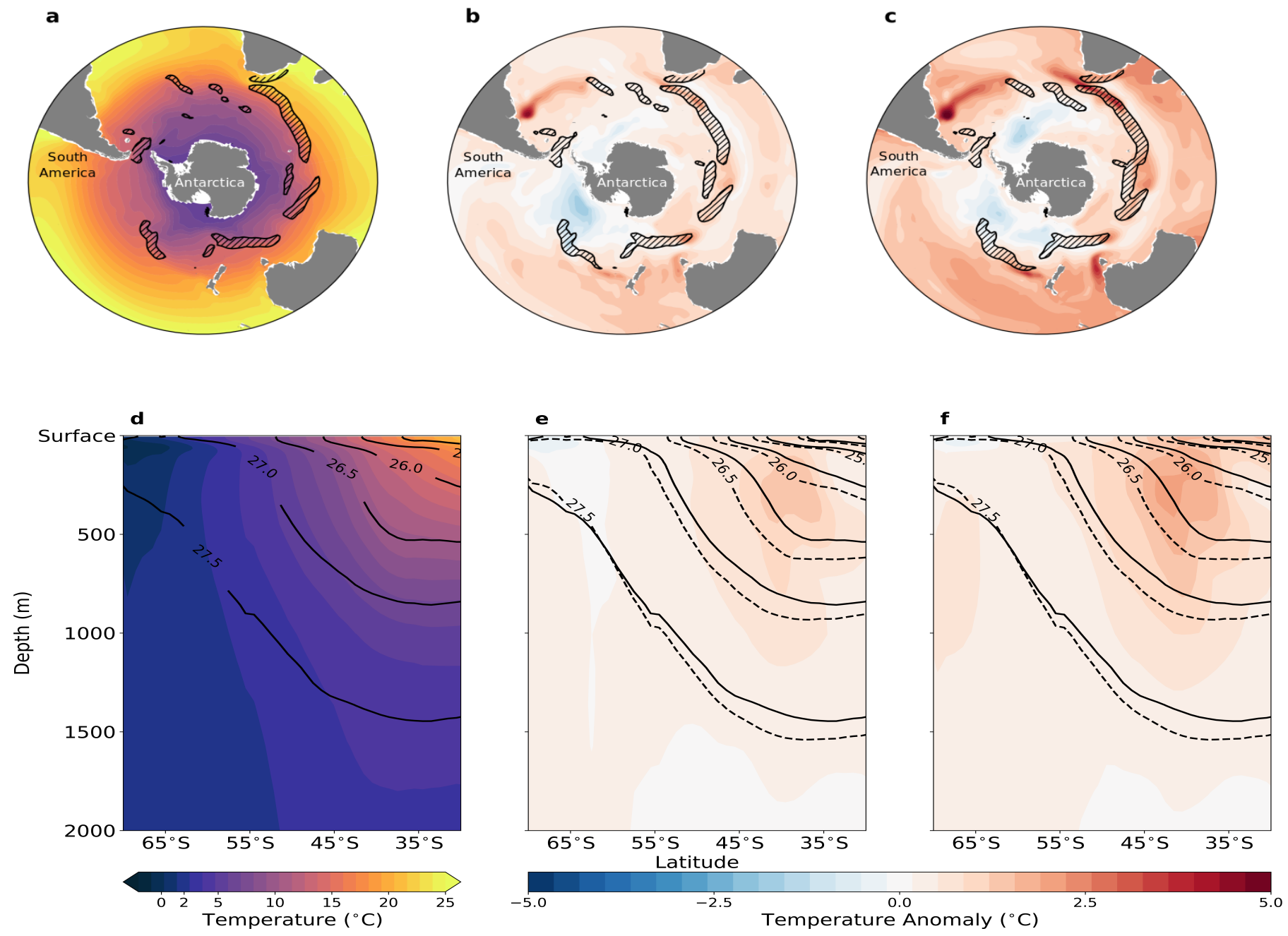

Figure 5. Climate change in the Southern Ocean. a the sea-surface temperature (SST) for the period 1985-2005 from a historical climate model simulation; $\mathbf{b}$ and $\mathbf{c}$ the SST anomaly for the period 2080-2100 (relative to 1985-2005) for a (b) medium (Representative Concentration Pathway 4.5); and (c) high (Representative Concentration Pathway 8.5) emissions scenarios. Hatched regions correspond to sea-surface height gradients greater than $10 \mathrm{~cm} / 100 \mathrm{~km}$ (indicative of fronts or strong surface currents). $\mathbf{d} ; \mathbf{e}$; and $\mathbf{f}$ as for $\mathbf{a}, \mathbf{b}$, and $\mathbf{c}$ but a longitudinal (zonal) mean section across the Southern Ocean. Solid lines show the density contours (isopycnals) for the period 1985-2005, while the dashed lines show isopycnals for the period 2080-2100 for the RCP4.5 (e) and RCP8.5 (f) scenarios. The climate model is the Geophysical Fluid Dynamics Laboratory $\mathrm{ESM}_{2 \mathrm{M}}^{97}$, part of the CMIP5 multi-model ensemble. 
The SST and SSH contours that are often used to track frontal positions are sensitive to large-scale thermal expansion and steric sea-level rise occurring as a result of global climate change ${ }^{95}$. As such, while the locations of a particular SST or SSH contour may have shifted, their spatial gradients are largely insensitive to changes in the ocean's broad-scale structure ${ }^{94}$. This more recent work has led to the new consensus that ACC fronts have not shifted southward in the past decades, and the observed warming is now explained by changes in the wind-driven overturning circulation that accumulates heat within the ACC ${ }^{8,98}$.

\subsection{Impact of frontal changes on ecosystems}

If ACC fronts were to shift south as a result of climatic change, there would be a number of ecological implications: the structure and environmental conditions the Southern Ocean's bioregions would likely change ${ }^{9,62}$; there would be modifications in the distribution of nutrients and phytoplankton that form the base of the trophic $w_{e b}{ }^{62}$; and changes in distance required for animals to travel from breeding and moulting sites to foraging grounds ${ }^{9,68,69,99}$.

Studies seeking to understand the ecological implications of frontal shifts frequently employ global front definitions, which may not be appropriate for the study of variability and change in ACC fronts. Additionally, more recent research has highlighted that fine-scale features, such as eddies and submeso-scale currents, are as important as the meso-scale fronts for certain species ${ }^{21,83}$, and that these features are unlikely to be represented in the climate change projections from coarse resolution climate models ${ }^{89}$.

Future projections of Southern Ocean climate are uncertain, and numerous phenomena associated with ACC fronts of biological significance, such as the strength of the eddy field and the role of fronts as barriers to mixing, are potentially impacted by climate change. In addition, some climate projection predict a decoupling of the biogeochemical fronts from the physical fronts ${ }^{47}$, which would have implications for animals that use temperature as a proxy for prey availability ${ }^{67}$. Therefore, while fronts might not shift meridionally, some aspects of the habitat are likely to change.

\section{The Southern Ocean Fronts Users' Guide}

The rapid change in our understanding of the ACC, its fronts, and how they shape Southern Ocean ecosystems has resulted in confusion. How best one can proceed with a study of Southern Ocean physics, chemistry or biology? Which frontal definition should one use and why? How can one infer and attribute changes in the ACC? However, despite the complex nature of the ACC and its ecosystems, there has been extraordinary progress over the last decade, made possible primarily through the expansion of the Southern Ocean Observing System (SOOS) ${ }^{100}$. Continued progress will depend on effective exploitation of these new data systems. To facilitate this, we now present some broad advice to aide researchers.

\section{Defining ACC fronts and jets}

The choice of frontal definition can have a large impact on the results of a study, with particularly strong implications for the study of variability and change ${ }^{12,35}$. "Local" definitions derive all information required for their definition from the neighbourhood of the front itself, while "global" definitions, such as the contour method", define fronts using information from a wide geographic region. We emphasis that there is no "correct" frontal definition; the choice of a definition should always be guided by the objectives of the study and the available data. The advantages and disadvantages of each approach, and potential use cases are summarized in Table 1. For studies of time-averaged or broad-scale properties, global methods have several advantages: they are able to link jets and the hydrographic fronts, and their continuous representation allows geographically distant frontal features to be connected. Global type definitions are also generally useful for linking surface fields observable by satellite with interior water-masses ${ }^{4,31,34}$, and for defining along-front coordinate systems ${ }^{24,29}$.

Local definitions, by contrast, do not require the number the fronts to be specified in advance, and might better reflect regionally localized dynamics. However, interpreting their results is less straightforward than for global methods. We favour a probabilistic interpretation of frontal locations: instead of seeking to identify the location of a front at any given time, one should instead determine an envelope of where fronts are likely to be found over a time-period of interest. An example of this approach is presented in Fig. 4.

\section{Methodological choices for the study of variability and change}

The assessment of shifts in the location of Southern Ocean fronts has been mired in controversy over the last decade, with disagreement over the interpretation regarding the observed changes in the ACC (see section 4). The root cause of this controversy stems from the methodological differences between studies that find frontal shifts in the observation record, and 


\begin{tabular}{|c|c|c|}
\hline & Global & Local \\
\hline Example Definition & $\begin{array}{l}\text { Water mass criteria } \\
\text { Contour fitting } 4,5,7\end{array}$ & $\begin{array}{l}\text { Gradient thresholding }{ }^{12,27,35,39} \\
\text { Skewness/Kurtosis }{ }^{27,42} \\
\text { Probability Density Functions } \\
\text { (PDFs) }^{14,23} \text { Profile similarity/clustering } \\
\text { Pr,44 }\end{array}$ \\
\hline Advantages & $\begin{array}{l}\text { Accurate time mean locations }{ }^{5,12} \\
\text { Smooth, continuous fronts }{ }^{32} \\
\text { Links distant regions }^{32} \\
\text { Links jets to water } \\
\text { masses/hydrography } \\
\text { Simple to interpret }^{7,69}\end{array}$ & $\begin{array}{l}\text { Unambiguous definition }{ }^{12,25} \\
\text { Identifies changes in frontal struc- } \\
\text { ture } \\
\text { Identifies mixing barriers }^{13} \\
\text { No spurious variability }{ }^{35} \\
\text { Number of fronts can vary spatio- } \\
\text { temporally } 25,35\end{array}$ \\
\hline Disadvantages & $\begin{array}{l}\text { Imperfect tracking of high gradients } \\
\text { Spurious variability } \\
\text { Sensitivity to sea-level rise/warming }^{95} \\
\text { Must choose number of fronts in ad- } \\
\text { vance }^{24} \\
\text { Does not represent changes in frontal } \\
\text { structure }^{25,35}\end{array}$ & $\begin{array}{l}\text { Sensitive to noise/eddies } \\
\text { Must specify a threshold parameter }{ }^{12} \\
\text { Difficult to interpret } \\
\text { Difficult to link jets to hydrol- } \\
\text { ogy/water masses }{ }^{12}\end{array}$ \\
\hline
\end{tabular}

Table 1. A comparison between standard frontal definitions

those that do not. Typically, studies that have found long term frontal shifts used contour type methods, while those that did not, employed local type definitions. Given this controversy, we urge all researchers to be extremely prudent when assessing changes in the ACC's frontal structure. Readers are advised to carefully consider their choice of frontal definition, as naïve application of the contour method can lead to spurious variability and trends in frontal locations ${ }^{95}$. In cases where fronts are not required to be continuous, we favour the use of local frontal definitions in studies of variability and change. However, if a continuous, global frontal definition is sought, we then strongly encourage researchers to demonstrate that the variability and trend provided by the chosen global definition do track variability and trends of the water-masses structures.

Southern Ocean fronts and the eddies responsible for their formation are mesoscale features. In order to represent the physics of jets, fronts, and eddies, ocean models must have horizontal grid spacing less than about $10 \mathrm{~km}$ over most of the Southern Ocean. Running ocean models at this resolution requires vast computational resources, currently impractical for long climate studies. Despite this, low-resolution climate models are still able to produce realistic broad scale water-mass distributions in the Southern Ocean and are still useful for assessing potential changes in the Southern Ocean environment ${ }^{89,98}$. They are, however, incapable of representing the fine-scale features of fronts and their outputs must be interpreted with care.

\section{Perspectives for the future}

Advances in physical oceanography made possible by new data sources and analysis techniques have begun to resolve previously contentious questions regarding the nature of Southern Ocean fronts. For example, the role of ACC fronts in shaping broad-scale heat fluxes, the upwelling and subducting of water-masses, and the distribution of nutrients throughout the global ocean are now broadly understood. Additionally, it is now broadly accepted that the mean positions of the ACC fronts have not changed their position in response to recent climate change. However, numerous areas of disagreement exist concerning fundamental questions. In particular, the relationship between surface features detected by satellites and hydrographic fronts is still unclear in all but a few special cases.

Despite this recent progress, much work remains to translate our improved understanding of the physics of the Southern Ocean into improved understanding of its ecosystems and its role in the greater climate system. For example, the role of fronts in shaping ecosystems and bioregions must now be reevaluated in light of our updated knowledge of their dynamics. In particular, clear relationships between filamentary fronts revealed by satellites, and productive environmental conditions capable of 
supporting complex marine ecosystems are yet to be demonstrated. The response (if any) of the ACC fronts to the ongoing climate change, and any downstream impact on the climate system through their influence on the Southern Ocean carbon sink or southward heat flux is also poorly understood and not well represented in climate models. Theoretical understanding of the mechanisms of front formation and variability also remains incomplete.

Progress on these questions remains hampered, as was so often the case in the past, by insufficient data. In particular, biogeochemical data, such as observations of dissolved oxygen, $\mathrm{CO}_{2}$, and nutrients, is severely limited. The future, however, holds great hope for further breakthroughs. In particular, the increasing number of Argo floats equipped with biogeochemical sensors, as well as improving capabilities of new observing platforms such as ocean gliders, promise to shed light on these and other outstanding questions. The utility of equipping marine animals with oceanographic instruments has only recently been realised, and continued exploitation of these data could also lead to new advances ${ }^{11}$.

However, in our opinion, the greatest obstacle to further progress on these and many other outstanding questions is the compartmentalisation of researchers into specialities. The complexity of the region severely limits the potential progress of a single domain specialist when seeking to make inferences regarding the system as a whole. As such, it is our view that the greatest potential for further progress lies in facilitating further cross-disciplinary collaboration. A successful example of this cross-disiplinary collaboration is the Marine Mammals Exploring the Oceans Pole to Pole project ${ }^{11}$, which equips marine mammals with miniature temperature and salinity sensors, and has yielded a plethora of new results. Projects such as these represent a "gold standard" for interdisiplinary collaboration.

\section{Acknowledgements}

$\mathrm{CC}$ received funding through the CSIRO Decadal Climate Forecasting Project (DCFP). AM acknowledges support from the ARC Centre of Excellence for Climate Extremes (CE170100023). The Ssalto/Duacs altimeter products were produced and distributed by the Copernicus Marine and Environment Monitoring Service (CMEMS) (http://www.marine.copernicus.eu).

\section{References}

1. Rintoul, S. R. \& Garabato, A. C. N. Dynamics of the Southern Ocean Circulation. In Siedler, G., Griffies, S. M., Gould, J. \& Church, J. A. (eds.) Ocean Circulation and Climate, vol. 103 of International Geophysics, 471 - 492, DOI: https://doi.org/10.1016/B978-0-12-391851-2.00018-0 (Academic Press, 2013).

2. Deacon, G. The Hydrology of the Southern Ocean. Discovery reports (Cambridge University Press, 1937).

3. Orsi, A. H., Whitworth, T. \& Nowlin, W. D. On the meridional extent and fronts of the Antarctic Circumpolar Current. Deep Sea Research Part I: Oceanographic Research Papers 42, 641 - 673, DOI: 10.1016/0967-0637(95)00021-W (1995).

4. Sokolov, S. \& Rintoul, S. R. Structure of Southern Ocean fronts at $140^{\circ}$ E. J. Mar. Syst. 37, 151 - 184, DOI: https://doi.org/10.1016/S0924-7963(02)00200-2 (2002).

5. Sokolov, S. \& Rintoul, S. R. On the relationship between fronts of the Antarctic Circumpolar Current and surface chlorophyll concentrations in the Southern Ocean. J. Geophys. Res. Ocean. 112, DOI: 10.1029/2006JC004072 (2007).

6. Grant, S., Constable, A., Raymond, B. \& Doust, S. Bioregionalisation of the Southern Ocean: Report of Experts Workshop (ACE-CRC and WWF Australia, 2006).

7. Bost, C. et al. The importance of oceanographic fronts to marine birds and mammals of the southern oceans. J. Mar. Syst. 78, 363 - 376, DOI: https://doi.org/10.1016/j.jmarsys.2008.11.022 (2009). Special Issue on Observational Studies of Oceanic Fronts.

8. Sallée, J.-B. Southern Ocean Warming. Oceanography 31, 52-62 (2018).

9. Constable, A. J. et al. Climate change and Southern Ocean ecosystems I: how changes in physical habitats directly affect marine biota. Glob. Chang. Biol. 20, 3004-3025, DOI: 10.1111/gcb.12623 (2014).

10. Rogers, A. et al. Antarctic futures: An assessment of climate-driven changes in ecosystem structure, function, and service provisioning in the southern ocean. Аnпи. Rev. Mar. Sci. 12, null, DOI: 10.1146/annurev-marine-010419-011028 (2019).

11. Treasure, A. et al. Marine mammals exploring the oceans pole to pole: A review of the meop consortium. Oceanography 30, 132-138, DOI: 10.5670/oceanog.2017.234 (2017).

12. Chapman, C. C. Southern Ocean jets and how to find them: Improving and comparing common jet detection methods. $J$. Geophys. Res. Ocean. 119, 4318-4339, DOI: 10.1002/2014JC009810 (2014). 
13. Naveira-Garabato, A. C., Ferrari, R. \& Polzin, K. L. Eddy stirring in the southern ocean. J. Geophys. Res. Ocean. 116, DOI: 10.1029/2010JC006818 (2011). This paper provides a detailed examination of Southern Ocean fronts' "mixing barrier" effect, central to their role in the climate system.

14. Thompson, A. F. \& Sallée, J.-B. Jets and topography: Jet transitions and the impact on transport in the antarctic circumpolar current. J. Phys. Oceanogr. 42, 956-972, DOI: 10.1175/JPO-D-11-0135.1 (2012).

15. Chapman, C. \& Sallée, J.-B. Isopycnal mixing suppression by the antarctic circumpolar current and the southern ocean meridional overturning circulation. J. Phys. Oceanogr. 47, 2023-2045, DOI: 10.1175/JPO-D-16-0263.1 (2017).

16. Morrison, A., Frölicher, T. \& L. Sarmiento, J. Upwelling in the Southern Ocean. Phys. Today 68, 27-32, DOI: 10.1063/PT.3.2654 (2015).

17. Stukel, M. R. et al. Mesoscale ocean fronts enhance carbon export due to gravitational sinking and subduction. Proc. Natl. Acad. Sci. 114, 1252-1257, DOI: 10.1073/pnas.1609435114 (2017).

18. Williams, R. G., Wilson, C. \& Hughes, C. W. Ocean and Atmosphere Storm Tracks: The Role of Eddy Vorticity Forcing. J. Phys. Oceanogr. 37, 2267-2289, DOI: 10.1175/JPO3120.1 (2007).

19. Chambers, D. P. Using kinetic energy measurements from altimetry to detect shifts in the positions of fronts in the Southern Ocean. Ocean. Sci. 14, 105-116, DOI: 10.5194/os-14-105-2018 (2018).

20. d'Ovidio, F., De Monte, S., Alvain, S., Dandonneau, Y. \& Lévy, M. Fluid dynamical niches of phytoplankton types. Proc. Natl. Acad. Sci. 107, 18366-18370, DOI: 10.1073/pnas.1004620107 (2010).

21. Lévy, M., Franks, P. J. S. \& Smith, K. S. The role of submesoscale currents in structuring marine ecosystems. Nat. Commun. 9, DOI: 10.1038/s41467-018-0705 (2018).

22. Belkin, I. M. \& Gordon, A. L. Southern Ocean fronts from the Greenwich meridian to Tasmania. J. Geophys. Res. Ocean. 101, 3675-3696, DOI: 10.1029/95JC02750 (1996).

23. Thompson, A. F., Haynes, P. H., Wilson, C. \& Richards, K. J. Rapid Southern Ocean front transitions in an eddy-resolving ocean GCM. Geophys. Res. Lett. 37, DOI: 10.1029/2010GL045386 (2010).

24. Langlais, C., Rintoul, S. \& Schiller, A. Variability and mesoscale activity of the Southern Ocean fronts: Identification of a circumpolar coordinate system. Ocean. Model. 39, 79 - 96, DOI: https://doi.org/10.1016/j.ocemod.2011.04.010 (2011).

25. Chapman, C. C. New Perspectives on Frontal Variability in the Southern Ocean. J. Phys. Oceanogr. 47, 1151-1168, DOI: 10.1175/JPO-D-16-0222.1 (2017).

26. Hughes, C. W. \& Ash, E. R. Eddy forcing of the mean flow in the southern ocean. J. Geophys. Res. Ocean. 106, 2713-2722, DOI: 10.1029/2000JC900332 (2001).

27. Hughes, C. W., Thompson, A. F. \& Wilson, C. Identification of jets and mixing barriers from sea level and vorticity measurements using simple statistics. Ocean. Model. 32, 44 - 57, DOI: https://doi.org/10.1016/j.ocemod.2009.10.004 (2010).

28. Dufour, C. O. et al. Role of mesoscale eddies in cross-frontal transport of heat and biogeochemical tracers in the southern ocean. J. Phys. Oceanogr. 45, 3057-3081, DOI: 10.1175/JPO-D-14-0240.1 (2015).

29. Chapman, C. \& Sallée, J.-B. Can we reconstruct mean and eddy fluxes from Argo floats? Ocean. Model. 120, 83 - 100, DOI: https://doi.org/10.1016/j.ocemod.2017.10.004 (2017).

30. Rintoul, S. The global influence of localized dynamics in the Southern Ocean. Nature 558, DOI: 10.1038/s41586-018-0182-3 (2018).

31. Sallée, J. B., Speer, K. \& Morrow, R. Response of the Antarctic Circumpolar Current to Atmospheric Variability. J. Clim. 21, 3020-3039, DOI: 10.1175/2007JCLI1702.1 (2008).

32. Sokolov, S. \& Rintoul, S. R. Circumpolar structure and distribution of the Antarctic Circumpolar Current fronts: 1. Mean circumpolar paths. J. Geophys. Res. Ocean. 114, DOI: 10.1029/2008JC005108 (2009).

33. Sokolov, S. \& Rintoul, S. R. Circumpolar structure and distribution of the Antarctic Circumpolar Current fronts: 2. Variability and relationship to sea surface height. J. Geophys. Res. Ocean. 114, DOI: 10.1029/2008JC005248 (2009).

34. Kim, Y. S. \& Orsi, A. H. On the Variability of Antarctic Circumpolar Current Fronts Inferred from 1992-2011 Altimetry. J. Phys. Oceanogr. 44, 3054-3071, DOI: 10.1175/JPO-D-13-0217.1 (2014). 
35. Graham, R. M., de Boer, A. M., Heywood, K. J., Chapman, M. R. \& Stevens, D. P. Southern Ocean fronts: Controlled by wind or topography? J. Geophys. Res. Ocean. 117, DOI: 10.1029/2012JC007887 (2012). Describes in detail the problems with "global" methods for studying the variability, and the insensitivity of fronts to changes in wind forcing.

36. Thompson, A. F., Haynes, P. H., Wilson, C. \& Richards, K. J. Rapid Southern Ocean front transitions in an eddy-resolving ocean GCM. Geophys. Res. Lett. 37, DOI: 10.1029/2010GL045386 (2010).

37. Rhines, P. B. Jets. Chaos: An Interdiscip. J. Nonlinear Sci. 4, 313-339, DOI: 10.1063/1.166011 (1994).

38. Meijers, A. et al. The role of ocean dynamics in king penguin range estimation. Nat. Clim. Chang. 9, 120, DOI: 10.1038/s41558-018-0388-2 (2019).

39. Moore, J. K., Abbott, M. R. \& Richman, J. G. Location and dynamics of the antarctic polar front from satellite sea surface temperature data. J. Geophys. Res. Ocean. 104, 3059-3073, DOI: 10.1029/1998JC900032 (1999).

40. Dong, S., Sprintall, J. \& Gille, S. T. Location of the antarctic polar front from amsr-e satellite sea surface temperature measurements. J. Phys. Oceanogr. 36, 2075-2089, DOI: 10.1175/JPO2973.1 (2006).

41. Freeman, N. M., Lovenduski, N. S. \& Gent, P. R. Temporal variability in the Antarctic Polar Front (2002-2014). J. Geophys. Res. Ocean. 121, 7263-7276, DOI: 10.1002/2016JC012145 (2016).

42. Shao, A. E., Gille, S. T., Mecking, S. \& Thompson, L. Properties of the Subantarctic Front and Polar Front from the skewness of sea level anomaly. J. Geophys. Res. Ocean. 120, 5179-5193, DOI: 10.1002/2015JC010723 (2015).

43. Pauthenet, E. et al. Seasonal Meandering of the Polar Front Upstream of the Kerguelen Plateau. Geophys. Res. Lett. 45, 9774-9781, DOI: 10.1029/2018GL079614 (2018).

44. Jones, D. C., Holt, H. J., Meijers, A. J. S. \& Shuckburgh, E. Unsupervised Clustering of Southern Ocean Argo Float Temperature Profiles. J. Geophys. Res. Ocean. 124, 390-402, DOI: 10.1029/2018JC014629 (2019).

45. Sallée, Jean-Baptiste and Matear, Richard and Rintoul, Stephen and Lenton, Andrew. Localized subduction of anthropogenic carbon dioxide in the Southern Hemisphere Oceans. Nat. Geosci. 5, DOI: 10.1038/NGEO1523 (2012).

46. Palter, J., Marinov, I., Sarmiento, J. \& Gruber, N. Large-Scale, Persistent Nutrient Fronts of the World Ocean: Impacts on Biogeochemistry. In Belkin, I. M. (ed.) Large-Scale Chemical Fronts of the World Ocean, DOI: 10.1007/698_2013_241 (Springer, 2013). Review of global biogeochemical fronts provides additional detail on processes described here, as well as a discussion of cross-frontal transport properties.

47. Freeman, N. M. et al. The Variable and Changing Southern Ocean Silicate Front: Insights From the CESM Large Ensemble. Glob. Biogeochem. Cycles 32, 752-768, DOI: 10.1029/2017GB005816 (2018).

48. Langlais, C. et al. Stationary Rossby waves dominate subduction of anthropogenic carbon in the Southern Ocean. Sci. Reports 7, DOI: 10.1038/s41598-017-17292-3 (2017).

49. Klocker, A. Opening the window to the southern ocean: The role of jet dynamics. Sci. Adv. 4, DOI: 10.1126/sciadv.aao4719 (2018). Model based study that demonstrates the importance of frontal jet interaction with bathymetry for driving upwelling and subduction.

50. Rintoul, S. et al. Choosing the future of Antarctica. Nature 558, DOI: 10.1038/s41586-018-0173-4 (2018).

51. Llort, J. et al. Evaluating Southern Ocean Carbon Eddy-Pump From Biogeochemical-Argo Floats. J. Geophys. Res. Ocean. 123, 971-984, DOI: 10.1002/2017JC012861 (2018). Using data from new Biogeochemical Argo floats, this study clarifies the role of mesoscale features, including fronts, on the subduction of surface water into the ocean interior. .

52. Venables, H. \& Moore, C. M. Phytoplankton and light limitation in the southern ocean: Learning from high-nutrient, high-chlorophyll areas. J. Geophys. Res. Ocean. 115, DOI: 10.1029/2009JC005361 (2010).

53. Bristow, L. A., Mohr, W., Ahmerkamp, S. \& Kuypers, M. M. Nutrients that limit growth in the ocean. Curr. Biol. 27, R474 - R478, DOI: https://doi.org/10.1016/j.cub.2017.03.030 (2017).

54. Sokolov, S. \& Rintoul, S. R. On the relationship between fronts of the antarctic circumpolar current and surface chlorophyll concentrations in the southern ocean. J. Geophys. Res. Ocean. 112, DOI: 10.1029/2006JC004072 (2007).

55. Thomalla, S. J., Fauchereau, N., Swart, S. \& Monteiro, P. M. S. Regional scale characteristics of the seasonal cycle of chlorophyll in the Southern Ocean. Biogeosciences 8, 2849-2866, DOI: 10.5194/bg-8-2849-2011 (2011). 
56. Graham, R. M., Boer, A. M. D., van Sebille, E., Kohfeld, K. E. \& Schlosser, C. Inferring source regions and supply mechanisms of iron in the southern ocean from satellite chlorophyll data. Deep. Sea Res. Part I: Oceanogr. Res. Pap. 104, 9 - 25, DOI: https://doi.org/10.1016/j.dsr.2015.05.007 (2015).

57. NASA Goddard Space Flight Center, O. B. P. G., Ocean Ecology Laboratory. moderate-resolution imaging spectroradiometer (modis) terra chlorophyll data (2018).

58. Hunt, B. P. \& Hosie, G. W. Zonal structure of zooplankton communities in the southern ocean south of australia: results from a 2150km continuous plankton recorder transect. Deep. Sea Res. Part I: Oceanogr. Res. Pap. 52, 1241-1271, DOI: https://doi.org/10.1016/j.dsr.2004.11.019 (2005).

59. Koubbi, P. et al. Spatial distribution and inter-annual variations in the size frequency distribution and abundances of pleuragramma antarcticum larvae in the dumont d'urville sea from 2004 to 2010. Polar Sci. 5, 225 - 238, DOI: https://doi.org/10.1016/j.polar.2011.02.003 (2011). CEAMARC: The Collaborative East Antarctic Marine Census for the Census of Antarctic Marine Life.

60. O'Toole, M., Guinet, C., Lea, M.-A. \& Hindell, M. Marine predators and phytoplankton: How elephant seals use the recurrent kerguelen plume. Mar. Ecol. Prog. Ser. 581, DOI: 10.3354/meps12312 (2017).

61. Garcia, H. E. et al. Volume 4: Dissolved Inorganic Nutrients (phosphate, nitrate, silicate). In Mishonov, A. (ed.) World Ocean Atlas 2018, 35, DOI: 10.1007/698_2013_241 (NOAA, 2018).

62. Deppeler, S. L. \& Davidson, A. T. Southern ocean phytoplankton in a changing climate. Front. Mar. Sci. 4, 40, DOI: 10.3389/fmars.2017.00040 (2017).

63. Charrassin, J.-B., Park, Y.-H., Maho, Y. L. \& Bost, C.-A. Penguins as oceanographers unravel hidden mechanisms of marine productivity. Ecol. Lett. 5, 317-319, DOI: 10.1046/j.1461-0248.2002.00341.x (2002).

64. Charrassin, J.-B. \& Bost, C. Utilisation of the oceanic habitat by king penguins over the annual cycle. Mar. Ecol. Prog. Ser. 221, 285-297 (2001).

65. Charrassin, J.-B., Park, Y.-H., Maho, Y. L. \& Bost, C.-A. Fine resolution 3D temperature fields off Kerguelen from instrumented penguins". Deep. Sea Res. Part I: Oceanogr. Res. Pap. 51, 2091 - 2103, DOI: https://doi.org/10.1016/j.dsr.2004.07.019 (2004).

66. Sokolov, S., Rintoul, S. R. \& Wienecke, B. Tracking the polar front south of new zealand using penguin dive data. Deep. Sea Res. Part I: Oceanogr. Res. Pap. 53, 591 - 607, DOI: https://doi.org/10.1016/j.dsr.2005.12.012 (2006).

67. Scheffer, A., Trathan, P. N. \& Collins, M. Foraging behaviour of king penguins (aptenodytes patagonicus) in relation to predictable mesoscale oceanographic features in the polar front zone to the north of south georgia. Prog. Oceanogr. 86, $232-245$, DOI: https://doi.org/10.1016/j.pocean.2010.04.008 (2010). Study of a marine predator that successfully integrates biotelemetry data with environmentally remote sensed data to conclusively reveal the interactions between biology and environmental conditions.

68. Péron, C., Weimerskirch, H. \& Bost, C.-A. Projected poleward shift of king penguins' ( $<\mathrm{i}>$ Aptenodytes patagonicus $</ \mathrm{i}>$ ) foraging range at the Crozet Islands, southern Indian Ocean. Proc. Royal Soc. B: Biol. Sci. 279, 2515-2523, DOI: 10.1098/rspb.2011.2705 (2012).

69. Cristofari, R. et al. Climate-driven range shifts of the king penguin in a fragmented ecosystem. Nat. Clim. Chang. 8, DOI: 10.1038/s41558-018-0084-2 (2018).

70. Hunt, G. L. J., Harrison, N. M. \& Cooney, R. T. The influence of hydrographic structure and prey abundance on foraging of least auklets. Stud. Avian Biol. 14, 7-22 (1990).

71. Woehler, E., Raymond, B. \& Watts, D. Convergence or divergence: Where do short-tailed shearwaters forage in the southern ocean? Mar. Ecol. Prog. Ser. 324, 261-270, DOI: 10.3354/meps324261 (2006).

72. Commins, M. L., Ansorge, I. \& Ryan, P. G. Multi-scale factors influencing seabird assemblages in the African sector of the Southern Ocean. Antarctic Sci. 26, 38-48, DOI: 10.1017/S0954102013000138 (2014).

73. Lea, M.-A. \& Dubroca, L. Fine-scale linkages between the diving behaviour of Antarctic fur seals and oceanographic features in the southern Indian Ocean. ICES J. Mar. Sci. 60, 990-1002, DOI: 10.1016/S1054-3139(03)00101-2 (2003).

74. Lea, M.-A. et al. Impacts of climatic anomalies on provisioning strategies of a southern ocean predator. Mar. Ecol. Prog. Ser. 310, 297-310, DOI: 10.3354/meps310077 (2006).

75. Guinet, C. et al. Spatial distribution of foraging in female Antarctic fur seals Arctocephalus gazella in relation to oceanographic variables: a scale-dependent approach using geographic information systems. Mar. Ecol. Prog. Ser. 219, 251-264, DOI: 10.3354/meps219251 (2001). 
76. Béhagle, N. et al. Acoustic micronektonic distribution is structured by macroscale oceanographic processes across $20-50^{\circ} \mathrm{S}$ latitudes in the South-Western Indian Ocean. Deep. Sea Res. Part I: Oceanogr. Res. Pap. 110, 20 - 32, DOI: https://doi.org/10.1016/j.dsr.2015.12.007 (2016).

77. Gordine, S. A., Fedak, M. A. \& Boehme, L. The importance of Southern Ocean frontal systems for the improvement of body condition in southern elephant seals. Aquatic Conserv. Mar. Freshw. Ecosyst. 29, 283-304, DOI: 10.1002/aqc.3183 (2019).

78. Weimerskirch, H., Å kesson, S. \& Pinaud, D. Postnatal dispersal of wandering albatrosses diomedea exulans: implications for the conservation of the species. J. Avian Biol. 37, 23-28, DOI: 10.1111/j.2006.0908-8857.03675.x (2006).

79. Bailleul, F., Cotte, C. \& Guinet, C. Mesoscale eddies as foraging area of a deep-diving predator, the southern elephant seal. Mar. Ecol. Prog. Ser. 408, 251-264, DOI: 10.3354/meps08560 (2010).

80. Della Penna, A., De Monte, S., Kestenare, E., Guinet, C. \& d'Ovidio, F. Quasi-planktonic behavior of foraging top marine predators. Sci. reports 5, 18063, DOI: 10.1038/srep18063 (2015).

81. Cotté, C., d'Ovidio, F., Dragon, A.-C., Guinet, C. \& Lévy, M. Flexible preference of southern elephant seals for distinct mesoscale features within the Antarctic Circumpolar Current. Prog. Oceanogr. 131, 46 - 58, DOI: https://doi.org/10.1016/j.pocean.2014.11.011 (2015).

82. Hindell, M. A. et al. Circumpolar habitat use in the southern elephant seal: implications for foraging success and population trajectories. Ecosphere 7, e01213, DOI: 10.1002/ecs2.1213 (2016).

83. Siegelman, L., O’Toole, M., Flexas, M., Rivière, P. \& Klein, P. Submesoscale ocean fronts act as biological hotspot for southern elephant seal. Sci. Reports 9, 5588, DOI: 10.1038/s41598-019-42117-w (2019). This paper exploits a modern and unique dataset to reveal insights into both physical and biological systems that influence marine mammal behaviour.

84. Nel, D. et al. Exploitation of mesoscale oceanographic features by Grey-headed Albatrosses (Thalassarche chrysostoma) in the southern Indian Ocean. Mar. Ecol. Ser. 217, 15-26, DOI: 10.3354/meps217015 (2001).

85. C. Swart, N., Gille, S., C. Fyfe, J. \& P. Gillett, N. Recent Southern Ocean warming and freshening driven by greenhouse gas emissions and ozone depletion. Nat. Geosci. 11, DOI: 10.1038/s41561-018-0226-1 (2018).

86. Jones, J. et al. Assessing recent trends in high-latitude Southern Hemisphere climate. Nat. Clim. Chang. 6, DOI: 10.1038/nclimate3103 (2016).

87. Fyfe, J. C. \& Saenko, O. A. Simulated changes in the extratropical Southern Hemisphere winds and currents. Geophys. Res. Lett. 33, DOI: 10.1029/2005GL025332 (2006).

88. Bracegirdle, T. J. et al. Assessment of surface winds over the Atlantic, Indian, and Pacific Ocean sectors of the Southern Ocean in CMIP5 models: historical bias, forcing response, and state dependence. J. Geophys. Res. Atmospheres $\mathbf{1 1 8 ,}$ 547-562, DOI: 10.1002/jgrd.50153 (2013).

89. Meijers, A. J. S. The Southern Ocean in the Coupled Model Intercomparison Project phase 5. Philos. Transactions Royal Soc. A: Math. Phys. Eng. Sci. 372, DOI: 10.1098/rsta.2013.0296 (2014).

90. Billany, W., Swart, S., Hermes, J. \& Reason, C. Variability of the Southern Ocean fronts at the Greenwich Meridian. $J$. Mar. Syst. 82, 304 - 310, DOI: https://doi.org/10.1016/j.jmarsys.2010.06.005 (2010).

91. Downes, S. M., Budnick, A. S., Sarmiento, J. L. \& Farneti, R. Impacts of wind stress on the Antarctic Circumpolar Current fronts and associated subduction. Geophys. Res. Lett. 38, DOI: 10.1029/2011GL047668 (2011).

92. Gille, S. T. Decadal-Scale Temperature Trends in the Southern Hemisphere Ocean. J. Clim. 21, 4749-4765, DOI: 10.1175/2008JCLI2131.1 (2008).

93. Meijers, A. J. S., Bindoff, N. L. \& Rintoul, S. R. Frontal movements and property fluxes: Contributions to heat and freshwater trends in the southern ocean. J. Geophys. Res. Ocean. 116, DOI: 10.1029/2010JC006832 (2011).

94. Böning, C., Dispert, A., Visbeck, M., Rintoul, S. \& Schwarzkopf, F. The Response of the Antarctic Circumpolar Current to recent climate change. Nat. Geosci. 1, DOI: 10.1038/ngeo362 (2008).

95. Gille, S. Meridional displacement of the Antarctic Circumpolar Current. Philos. transactions. Ser. A, Math. physical, engineering sciences 372, DOI: 10.1098/rsta.2013.0273 (2014).

96. Meijers, A. J. S. et al. Representation of the Antarctic Circumpolar Current in the CMIP5 climate models and future changes under warming scenarios. J. Geophys. Res. Ocean. 117, DOI: 10.1029/2012JC008412 (2012). 
97. Dunne, J. P. et al. GFDL's ESM2 Global Coupled Climate-Carbon Earth System Models. Part I: Physical Formulation and Baseline Simulation Characteristics. J. Clim. 25, 6646-6665, DOI: 10.1175/JCLI-D-11-00560.1 (2012).

98. Armour, K. C., Marshall, J. C., Scott, J., Donohoe, A. \& Newsom, E. R. Southern Ocean warming delayed by circumpolar upwelling and equatorward transport. Nat. Geosci. 9, 549-554, DOI: 10.1038/ngeo2731 (2016).

99. Bost, C. et al. Large-scale climatic anomalies affect marine predator foraging behaviour and demography. Nat. Commun. 6, DOI: $10.1038 /$ ncomms 9220 (2015).

100. Newman, L. et al. Delivering Sustained, Coordinated, and Integrated Observations of the Southern Ocean for Global Impact. Front. Mar. Sci. 6, 433, DOI: 10.3389/fmars.2019.00433 (2019). 